clindamycin. Most doctors will have received the report, based on 174 notifications of colitis attributed to antibiotics. Of these, over $80 \%$ were associated with lincomycin or clindamycin, though selective reporting may have caused other antibiotics to be under-represented-and, indeed, most cases were reported after 1974, when Tedesco's report of colitis in a tenth of patients treated with clindamycin sounded the alarm. ${ }^{22}$ The use of clindamycin should be reserved for treating serious infections (primarily deep staphylococcal sepsis), where it is specifically indicated and of proved value. It is an unusual paradox that an antibiotic-induced disease responds so readily to treatment with a second antimicrobial drug-but oral vancomycin itself has so far proved itself reassuringly safe and effective.

${ }^{1}$ Larson, H E, et al, British Medical fournal, 1977, 1, 1246.

2 Rifkin, G D, et al, Lancet, 1977, 2, 1103.

${ }^{3}$ Larson, H E, and Price, A B, Lancet, 1977, 2, 1312.

4 Bartlett, J G, et al, Fournal of Infectious Diseases, 1977, 136, 701.

- Bartlett, J G, et al, New England Fournal of Medicine, 1978, 298, 531.

6 George, R H, et al, British Medical fournal, 1978, 1, 695.

7 British Medical fournal, 1978, 1, 669.

${ }^{8}$ Kappas, A, et al, British Medical fournal, 1978, 1, 675.

- Rietra, P J G M, et al, Lancet, 1978, 2, 319.

10 George, W, Sutter, V L, and Finegold, S M, fournal of Infectious Diseases, $1977,136,822$.

1 Larson, H E, et al, Lancet, 1978, 1, 1063.

${ }_{12}$ Burdon, D W, et al, fournal of Antimicrobial Chemotherapy, 1979, 5, 307.

$13 \mathrm{Hafiz}, \mathrm{S}$, et al, Lancet, 1975, 1, 420.

14 Hall, I C, and O'Toole, E, American Fournal of Diseases of Children, 1935, 49, 390 .

${ }_{15}$ Marr, J J, Sans, M D, and Tedesco, F J, Gastroenterology, 1975, 69, 352

16 Smith, H, Bacteriological Reviews, 1977, 41, 475.

17 Tedesco, F, et al, Lancet, 1978, 2, 226.

18 Keighley, M R B, et al, British Medical fournal, 1978, 2, 1667.

19 Pashby, N L, Bolton, R P, and Sherriff, R J, British Medical fournal, $1979,1,1605$.

20 Keighley, M R B, et al, Lancet, 1978, 2, 1165.

21 Ramirez-Ronda, C H, Annals of Internal Medicine, 1974, 81, 860.

22 Tedesco, F J, Barton, R W, and Alpers, D H, Annals of Internal Medicine, $1974,81,429$.

${ }^{23}$ Committee on Safety of Medicines Adverse Reactions Series, June 1979.

\section{Acquired cerebral disorders of reading}

Alexia is the incapacity to understand written language as a consequence of a cerebral lesion and is usually the result of focal cortical damage or neuronal disconnection. Damage to the left angular gyrus down to the underlying white matter commonly results in alexia with associated inability to write (agraphia) and inevitably some difficulty with speech (aphasia). Allied abnormalities may include features of the Gerstmann syndrome, hemiparesis, and sensory loss affecting the right side of the body. Damage to the neighbouring posterior superior temporal gyrus will produce aphasia (Wernicke's sensory aphasia), which may be so severe that it causes secondary impairment of reading (aphasic alexia). The location of the temporal lesion is less clearly defined in patients with nominal aphasia, but in such cases the alexia reflects the semantic difficulties (semantic access alexia). ${ }^{1}$ If the angular gyrus is spared the patient may retain the ability to write; the rare syndrome of alexia without agraphia is due to interruption of pathways to the angular gyrus from the visual cortex and association areas. Occlusion of the left posterior cerebral artery will result in a right visual field defect from damage to the left visual cortex, and there will be disconnection of the corticocommissural fibres from the right visual cortex as they pass through the splenium of the corpus callosum. Occasionally when the damage is due to an arteriovenous malformation or a non-vascular lesion the left calcarine cortex may be spared, giving alexia without agraphia or hemianopsia.

The onset can be dramatic, though other intellectual capacities may appear totally unaffected. When the onset of the alexia is gradual in patients (such as epileptics) with longstanding brain damage some plasticity or adaptation may develop in the association pathways. Though the patient suffering from alexia without agraphia remains able to write, the writing has been likened to that of a normal person with his eyes closed. ${ }^{2}$ Often such patients will write better to dictation or when asked to write a spontaneously formulated paragraph than in copying. ${ }^{3}$ Sensory or motor defects are rarely present, but there may be defects in naming and selecting colours, an inability to read musical notes or numbers, nominal aphasia, and defects in topographical orientation. ${ }^{3}$ Neuronal disconnection also occurs with hemialexia, where there is unilateral alexia confined to the intact, non-dominant visual field following section, or a vascular lesion, of the splenium.

Neuropsychologists have long been concerned to identify the systems involved in reading. Classifications of linguistic difficulties usually emphasise three separate stages: visual recognition of letters and words, conversion of these symbols into word sounds (phonemes), and semantic comprehension. These may not occur in sequence but form a dual encoding system with alternative pathways. ${ }^{4}$ Faulty visual recognition may be a primary defect in alexia-almost all alexics have some difficulty in recognising letters in space. Many cannot orientate the letters or recognise them as graphic symbols. ${ }^{5}$ Letter blindness and word blindness can be regarded as separate defects dependent on different integrative activities of the visual cortex and association areas; and Albert et al ${ }^{6}$ described an alexic patient who was still able to spell words orally and to recognise orally spelled words. Such deficiencies do not, however, necessarily indicate a preauditory lesion: letter blindness without word blindness is frequently seen in aphasic patients, in whom nominal difficulties affect the comprehension of written words. Semantic difficulties suggesting a partial comprehension of words may cause paralexia, in which a paraphrase or semantic equivalent is used in place of the printed word: for example, "kitten" is read as "small cat." Defects in word comprehension and word retrieval may derive from the selective impairment of a lexicon or semantic memory. ${ }^{7}$ When the defect is in phonemic conversion there may be both visual and derivational semantic errors, but, as with the patient described by Shallice and Warrington, ${ }^{8}$ there may also be ability to read concrete nouns coexisting with inability to read abstract ones. Nouns were in general better read than adjectives, which in turn were better read than verbs, other grammatical categories being extremely poorly read.

The different errors found in patients with alexia-visual, phonemic, and semantic-are reflected in the reading errors of normal individuals, both adults and children, ${ }^{4}$ thereby increasing the relevance of the theoretical linguistics of Chomsky and others to neurological problems. As yet, however, even arduous individual therapy, demanding much concentration from the patient and ingenuity from the therapist, usually produces much less improvement in such patients than in the developmentally retarded reader.

Alexic disorders must be differentiated from the pseudoalexias. These are more mundane conditions that present clinically as severe difficulties in reading that do not conform to the exact definition of alexia. The pseudoalexias include 
inability to read aloud due to conduction aphasia or to Broca's motor aphasia (by definition alexia refers to comprehension), incorrect reading of part of a word (as with a visual field defect or neglect), unrecognised developmental dyslexia, mental retardation, confabulation in psychiatric disorders, confusional states, and psychogenic disorders such as schizophrenia. ${ }^{3}$

1 Warrington, E K, and Shallice, T, Brain, 1979, 102, 43.

2 Martin, J P, Proceedings of the Royal Society of Medicine, 1954, 47, 293.

3 Benson, D F, and Geschwind, N, in Handbook of Clinical Neurology, vol 4, ed P J Vinken and G W Bruyn, p 112. Amsterdam, North Holland Publ Co, 1969.

4 Marshall, J C, and Newcombe, F, Fournal of Psycholinguistic Research, $1973,2,175$.

${ }^{3}$ Alajouanine, T, Lhermitte, F, and Ribaucourt-Ducarne, B de, in Les Grandes Activités du Lobe Occipital, ed T Alajouanine et al. Paris, Masson et Cie, 1960.

6 Albert, M L, et al, Brain, 1973, 96, 317.

7 Coughlan, A, and Warrington, E K, Brain, 1978, 101, 163.

${ }^{8}$ Shallice, T, and Warrington, E K, Quarterly fournal of Experimental Psychology, 1975, 27, 187.

\section{Alcohol-dependent doctors}

In common with many other countries Britain is experiencing an epidemic of alcohol dependency, ${ }^{1}$ and doctors seem to be unusually susceptible. ${ }^{2-5} \mathrm{~A}$ careful study in Scotland showed that the first-admission rate for alcohol dependence was $2 \cdot 7$ times higher among doctors than controls in social class $1 .^{2}$ The death rate of doctors from cirrhosis of the liver is $3 \frac{1}{2}$ times that of the general population in England and Wales. ${ }^{5}$ One study has estimated that 13600-22 000 doctors in the United States are alcohol dependent at some stage in their career. ${ }^{4}$ Whatever the exact figures in Britain, the problem is large.

Most studies suggest that alcohol-dependent doctors do badly. ${ }^{4}$ They present late for treatment and often have to be compelled to accept it. Not only do doctors have difficulty recognising their problem but they are also inclined to prescribe for themselves, and this often leads to concomitant drug addiction. ${ }^{45}$ When in hospital they are difficult to manage and often discharge themselves against medical advice. ${ }^{4}$ The ultimate prognosis appears to be poor, and suicide is common. ${ }^{5}$

In North America many programmes have been devised for treating alcohol dependency in doctors, and these are now working. In Britain, in contrast, the machinery for both curtailing and helping the alcohol-dependent doctor is sadly deficient. North Americans talk of the "impaired physician," and already the American Medical Association has held three conferences on the problem of dealing with him. An organisation in Oregon for helping the impaired physician is described by $\mathrm{Dr}$ Crawshaw in this issue ( $\mathrm{p} \mathrm{372)}$ ). Most of the Canadian states have implemented some kind of treatment scheme. ${ }^{6}$

Experience in North America has shown the formidable difficulties encountered in these schemes. $^{7}$ Regulatory authorities are often ambivalent whether the impaired doctor is mad or bad. Colleagues, police, patients, nurses, and employers all collude in ignoring the obvious problems of the drinking doctor, wishing to help him, and then are often scared to report him, fearing recrimination. Colleagues wishing to take action are also often ignorant of the methods available. Nevertheless, many of the newer North American schemes now actively seek out impaired doctors, one result being that, whereas in 1971 only 119 doctors in the United States were found unfit to practise, by 1977 the number had risen to $685 .^{6}$

The Medical Society of the State of New York has thought carefully about these problems and introduced two parallel systems to help and curtail the impaired doctor. ${ }^{7}$ The principles of these systems impressed the Alment Committee of Enquiry into Competence to Practise. ${ }^{8}$ The non-coercive system keeps no records, produces no reports, has no statutory power, and exists primarily to encourage the alcohol-dependent doctor to recognise his problem and seek help. Under the coercive system the impaired doctor's licence can be suspended if he does not accept "monitored treatment." Doctors in New York believe that the patient should be able to choose his own psychiatrist or doctor; but, to ensure that the public interest is observed, a member of the division of professional conduct monitors the progress of treatment.

In its evidence to the Merrison Inquiry into the Regulation of the Medical Profession the General Medical Council reported that a significant proportion of disciplinary cases in the previous decade had concerned psychiatrically ill doctors, of whom the largest category were those addicted to alcohol or drugs. ${ }^{9}$ In 1960 the then Ministry of Health had issued advice $^{10}$ to medical staff committees about setting up an informal machinery-the "three wise men" procedure-"to assist in preventing harm to patients resulting from physical or mental disability, including addiction, of hospital medical or dental staff." NHS general practitioners have had a rather more formal procedure for handling sick GPs, in which local medical committees play a part. ${ }^{11}$ But the Merrison Committee was not convinced of the effectiveness of these procedures, strongly criticising the "very uncoordinated" NHS machinery for dealing with the sick doctor. It recommended the introduction of a new scheme-similar, in fact, to that operating in New York State. The proposal was for strengthened local "supportive arrangements" within the NHS to persuade sick doctors to accept treatment, backed up by a central health committee of the GMC with power to suspend or make conditional the doctor's registration. The reconstructed GMC, with this new health committee, is shortly to take office and the present GMC has been consulting with the profession since November 1978 about the workings of the national and local machinery. The outcome should be more effective help for the alcohol-dependent doctor and more protection for his patients.

\footnotetext{
' Alcohol and Alcoholism. Report of a Special Committee of the Royal College of Psychiatrists. London, Tavistock, 1979.

2 Murray, R M, British Medical fournal, 1976, 4, 1537.

3 Vincent, M O, et al, Canadian Medical Association fournal, 1969, 100, 403.

4 Bissel, L, and Jones, R W, American Fournal of Psychiatry, 1976, 133, 1142.

5 Murray, R M, British Fournal of Psychiatry, 1977, 131, 1.

6 Henry, S, Canadian Medical Association Fournal, 1979, 120, 989.

${ }^{7}$ New York State Fournal of Medicine, 1975, 75, 420.

${ }^{8}$ Competence to Practise. London, Committee of Enquiry into Competence to Practise, 1976. (Alment Report.)

${ }^{9}$ British Medical fournal, Supplement, 1973, 3, 170.

10 Ministry of Health circular HM(60)45, 1960.

11 NHS (General Medical and Pharmaceutical Services) Regulation 1974, sch 1, para 40. London, HMSO, 1974.
} 